\title{
Attitudes of cancer patients, family caregivers, oncologists and members of the general public toward critical interventions at the end of life of terminally ill patients
}

\author{
Young Ho Yun MD PhD, Kyung Hee Han MD, Sohee Park PhD, Byeong Woo Park MD PhD, \\ Chi-Heum Cho MD PhD, Sung Kim MD PhD, Dae Ho Lee MD PhD, Soon Nam Lee MD PhD, \\ Eun Sook Lee MD PhD, Jung Hun Kang MD PhD, Si-Young Kim MD PhD, Jung Lim Lee MD PhD, \\ Dae Seog Heo MD PhD, Chang Geol Lee MD PhD, Yeun Keun Lim MD PhD, Sam Yong Kim MD PhD, \\ Jong Soo Choi MD PhD, Hyun Sik Jeong MD PhD, Mison Chun MD PhD
}

\begin{abstract}
Background: Whereas most studies have focused on euthanasia and physician-assisted suicide, few have dealt comprehensively with other critical interventions administered at the end of life. We surveyed cancer patients, family caregivers, oncologists and members of the general public to determine their attitudes toward such interventions.
\end{abstract}

Methods: We administered a questionnaire to four groups about their attitudes toward five end-of-life interventions - withdrawal of futile life-sustaining treatment, active pain control, withholding of life-sustaining measures, active euthanasia and physician-assisted suicide. We performed multivariable analyses to compare attitudes and to identify sociodemographic characteristics associated with the attitudes.

Results: A total of 3840 individuals - 1242 cancer patients, 1289 family caregivers and 303 oncologists from 17 hospitals, as well as 1006 members of the general Korean population participated in the survey. A large majority in each of the groups supported withdrawal of futile life-sustaining treatment $(87.1 \%-94.0 \%)$ and use of active pain control (89.0\%-98.4\%). A smaller majority $(60.8 \%-76.0 \%)$ supported withholding of life-sustaining treatment. About $50 \%$ of those in the patient and general population groups supported active euthanasia or physician-assisted suicide, as compared with less than $40 \%$ of the family caregivers and less than $10 \%$ of the oncologists. Higher income was significantly associated with approval of the withdrawal of futile life-sustaining treatment and the practice of active pain control. Older age, male sex and having no religion were significantly associated with approval of withholding of life-sustaining measures. Older age, male sex, having no religion and lower education level were significantly associated with approval of active euthanasia and physicianassisted suicide

Interpretation: Although the various participant groups shared the same attitude toward futile and ameliorative end-of-life care (the withdrawal of futile life-sustaining treatment and the use of active pain control), oncologists had a more negative attitude than those in the other groups toward the active ending of life (euthanasia and physician-assisted suicide).
A s more attention turns to when and how the lives of terminally ill patients end in the clinical setting, debate about the issues of euthanasia and physician-assisted suicide grows. ${ }^{1-5}$ Euthanasia has been discussed in Europe and the United States for more than a century, and the public has become more accepting of it. ${ }^{4-10}$ Announcing its first-ever ruling in favour of an unconscious patient's right to die with dignity, the Korean Supreme Court recently ruled that doctors of an elderly woman in a persistent vegetative state remove the artificial respirator from her on the basis of her presumed wishes. ${ }^{11}$ A public debate aimed at legalizing withdrawal of futile life-sustaining treatment, exposure to stories of dying patients in the mass media, and the court's decision may have led to a greater awareness of, and sensibility toward, the rights of terminally ill patients. In 2000 , only $16.5 \%$ of 535 Korean oncologists surveyed said that they would prescribe morphine for severe cancer pain, and more than half of 655 patients who had pain said they had inadequate pain management. ${ }^{12}$

Although much has been written about attitudes toward how the general public would choose to die in the clinical setting, ${ }^{4,13}$ most studies have focused on only euthanasia and physicianassisted suicide. ${ }^{14-18}$ We conducted a large survey
Competing interests: None declared.

This article has been peer reviewed.

Correspondence to: Dr. Young Ho Yun, lawyun08@ncc.re.kr

CMAJ 2011. DOI:10.1503 /cmaj.110020 
to examine attitudes among cancer patients, family caregivers, oncologists and members of the general public toward critical interventions at the end of life of terminally ill patients.

\section{Methods}

\section{Study population}

In this multicentre study, we surveyed the following four groups from 2008 through 2009: cancer patients, family caregivers, oncologists and members of the general Korean population.

\section{Patients}

Oncologists at 17 hospitals (16 general hospitals and Korea's National Cancer Center) were asked to identify cancer patients at outpatient clinics. Patients were eligible to participate if they were 20 years or older and were able to fill out questionnaires, communicate with an interviewer, understand the intent of the study and provide informed consent. Of the 1378 consecutive patients identified, 132 were excluded: 27 had serious illness (e.g., dyspnea) or were incompetent, 21 had speech or hearing limitations, and 84 refused to participate because of time constraints or because they thought participation would be an inconvenience or would entail an invasion of privacy. Of the 1246 patients who were interviewed, 4 returned incomplete questionnaires; the remaining 1242 patients were included in our study (response rate $90.1 \%$ of those considered eligible).

\section{Family caregivers}

For each patient included in the study, the relative who provided the patient with the most assistance was given information about the study and interviewed by a trained research assistant. Those who

\section{Box 1: Definitions of terms used in questionnaire to determine attitudes toward critical interventions at the end of life of terminally ill patients}

Withdrawal of futile life-sustaining treatment

Active pain control Withholding of life-sustaining measures

Active euthanasia suicide
The practice of allowing a patient at the end of life to die naturally by withdrawing life-sustaining treatment deemed medically futile without the primary intention of ending the patient's life

The practice of using opioids to relieve pain The practice of withholding from an unconscious patient (e.g., one in a vegetative state) drugs, life-support systems or other life-prolonging treatments with the primary intention of ending the patient's life

The practice of injecting a patient with a lethal dose of a medication with the primary intention of ending the patient's life

The practice of providing a competent patient with a prescription for a medication that the patient can use with the primary intention of ending life were not well enough to fill out a questionnaire, communicate with an interviewer or understand the study well enough to provide informed consent were ineligible. Of the 1355 eligible family caregivers, 58 were excluded because of speech or hearing limitations or because they were not well or did not sign a consent form. Of the remaining 1297 caregivers who were interviewed, 8 did not complete the questionnaire; the remaining 1289 were included in our study (response rate $95.1 \%$ of those considered eligible).

\section{Oncologists}

We obtained a list of 374 oncologists at the 17 hospitals from the Korean Cancer Association. Seventy-one refused to participate (primarily because of a busy schedule). Of the remaining $303(81.0 \%)$, all completed the questionnaire.

\section{General population}

Our goal was to survey 1000 members of the general Korean public who were 20-70 years of age, distributed over the 17 city and local districts. At each site, we constructed the sample in two strata (by age and sex), according to the guidelines of the 2005 Census of Korea. Starting with 1325 randomly selected residential telephone numbers, we obtained our final sample using a probabilityproportional-to-size technique, which is a widely recommended method for obtaining a representative national sample. ${ }^{19}$ The survey was conducted by telephone by Korea Research Inc. using a structured questionnaire and professional interviewers. A total of 1006 people were interviewed (response rate $75.9 \%$ ).

\section{Questionnaire}

The questionnaire was based on those used in previous studies of this issue., ${ }^{5,911,20,21}$ It was designed to query participants about their attitudes toward five end-of-life interventions - withdrawal of futile life-sustaining treatment, active pain control, withholding of life-sustaining measures, active euthanasia and physician-assisted suicide (as defined in Box 1). Possible scores ranged from 1 to 4 for each of the items ( $1=$ strongly agree, $2=$ agree, $3=$ disagree and $4=$ strongly disagree). To agree meant to approve of the practice. The questionnaire was also designed to collect demographic information (sex, age, education level, employment status, religion and income) and information on attitudes toward the disclosure of terminal status, hospice palliative care and advance directives.

There was no coercion to participate in this survey, but the patient's physician, as a coresearcher, recommended completion of the questionnaire. No participants were paid, all 
(except for the general population) provided written informed consent, and the institutional review boards of the 17 hospitals approved the protocol.

\section{Statistical analysis}

We report sociodemographic variables as numbers and percentages. If the response to any question was "strongly agree" or "agree," the participant was classified as approving the manner of death in question.
Answers were treated as dichotomous outcomes, and we used a logistic regression model to test associations of agreement with the sociodemographic characteristics of the respondents. We performed multivariable analyses as follows. First, in the exploratory stage of variable selection for the sociodemographic characteristics (age, sex, education level, employment status, religion and monthly income), we applied a forward (and backward) stepwise procedure to fit a logistic

\begin{tabular}{|c|c|c|c|c|}
\hline \multirow[b]{2}{*}{ Characteristic } & \multicolumn{4}{|c|}{ Group; no. (\%) } \\
\hline & $\begin{array}{c}\text { Cancer patients } \\
n=1242\end{array}$ & $\begin{array}{l}\text { Family caregivers } \\
\qquad n=1289\end{array}$ & $\begin{array}{c}\text { Oncologists } \\
n=303\end{array}$ & $\begin{array}{c}\text { General public } \\
n=1006\end{array}$ \\
\hline Sex & $n=1242$ & $n=1289$ & $n=303$ & $n=1006$ \\
\hline Male & $588(47.3)$ & $483(37.5)$ & $247 \quad(81.5)$ & $507(50.4)$ \\
\hline Female & $654(52.7)$ & $806(62.5)$ & $56 \quad(18.5)$ & $499(49.6)$ \\
\hline Age, yr & $n=1234$ & $n=1283$ & $n=300$ & $n=1006$ \\
\hline$\leq 39$ & $161(13.0)$ & $527(41.1)$ & $152(50.7)$ & $483(48.0)$ \\
\hline $40-49$ & $355(28.8)$ & $330(25.7)$ & $89 \quad(29.7)$ & $249(24.8)$ \\
\hline$\geq 50$ & $718(58.2)$ & $426(33.2)$ & 59 (19.7) & $274(27.2)$ \\
\hline Education & $n=1227$ & $n=1286$ & $n=303$ & $n=1006$ \\
\hline Middle school or less & $288(23.5)$ & $156(12.1)$ & 0 & $128(12.7)$ \\
\hline High school & $524(42.7)$ & $467(36.3)$ & 0 & $383(38.1)$ \\
\hline College or higher & $415(33.8)$ & $663(51.6)$ & $303(100.0)$ & $495(49.2)$ \\
\hline $\begin{array}{l}\text { Employed at time } \\
\text { of diagnosis }\end{array}$ & $n=1232$ & $n=1284$ & $n=303$ & $n=1006$ \\
\hline Yes & $524(42.5)$ & $686(53.4)$ & $303(100.0)$ & $470(46.7)$ \\
\hline No & $708(57.5)$ & $598(46.6)$ & 0 & $536(53.3)$ \\
\hline Religion & $n=1232$ & $n=1280$ & $n=302$ & $n=1006$ \\
\hline Christian & $534(43.3)$ & $564(44.1)$ & $190 \quad(62.9)$ & 399 (39.7) \\
\hline Buddhist & $297(24.1)$ & $316(24.7)$ & $21 \quad(7.0)$ & $209(20.8)$ \\
\hline Other & $41 \quad(3.3)$ & $35 \quad(2.7)$ & 0 & $22(2.2)$ \\
\hline None & $360(29.2)$ & $365(28.5)$ & $91 \quad(30.1)$ & $376(37.4)$ \\
\hline $\begin{array}{l}\text { Monthly income, } \\
\text { in } 1000 \text { Korean won }\end{array}$ & $n=1203$ & $n=1268$ & $n=303$ & $n=914$ \\
\hline$\leq 150$ & $371(30.8)$ & $244(19.2)$ & 0 & 255 (27.9) \\
\hline $151-300$ & $459(38.2)$ & $507(40.0)$ & 0 & $352(38.5)$ \\
\hline$>300$ & $373(31.0)$ & $517(40.8)$ & $303(100.0)$ & 307 (33.6) \\
\hline Type or site of cancer & $n=1233$ & $n=1273$ & & \\
\hline Breast & $303(24.6)$ & $178(14.0)$ & & \\
\hline Stomach & $236(19.1)$ & $289(22.7)$ & & \\
\hline Lung & $111 \quad(9.0)$ & $172(13.5)$ & & \\
\hline Colon & $107 \quad(8.7)$ & $128(10.1)$ & & \\
\hline Leukemia & $96 \quad(7.8)$ & $76 \quad(6.0)$ & & \\
\hline Cervical & $59 \quad(4.8)$ & $40 \quad(3.1)$ & & \\
\hline Liver & $46 \quad(3.7)$ & $61 \quad(4.8)$ & & \\
\hline Bladder & $9 \quad(0.7)$ & $10(0.8)$ & & \\
\hline Other & $266(21.6)$ & $319(25.1)$ & & \\
\hline
\end{tabular}


regression model with an entry (and removal) level of 0.15 . We also included variables (age, sex, education level, religion and monthly income) that showed statistical significance at the 0.10 level in the univariable model. Finally, we used hierarchical variable selection to select a statistical best-fit and clinically plausible model.

Because the four participant categories were associated with sociodemographic variables, it was not possible to estimate some parameters when all variables were included in the logistic regression model together. Hence, we present the effect of the participants' category separately in a graph and table.

\section{Results}

Table 1 lists the sociodemographic characteristics of the 1242 patients, 1289 family caregivers,
303 oncologists and 1006 members of the general public who participated in the survey.

Table 2 shows the results of the univariable and multivariable logistic regression analyses of factors associated with approval of the five critical interventions studied. After adjustment for possible confounders, we found that older age and higher income were significantly associated with approval of withdrawal of futile lifesustaining treatment. Higher income was the only characteristic associated with approval of active pain control. Older age, male sex and having no religion were associated with approval of withholding of life-sustaining measures. Older age, male sex, having no religion and lower education level were associated with approval of active euthanasia and physician-assisted suicide.

Most of the participants in each of the four study groups approved of the withdrawal of futile

\begin{tabular}{|c|c|c|c|c|c|}
\hline Characteristict & $\begin{array}{l}\text { Withdrawal of futile } \\
\text { life-sustaining treatment }\end{array}$ & $\begin{array}{c}\text { Active } \\
\text { pain control }\end{array}$ & $\begin{array}{l}\text { Withholding of life- } \\
\text { sustaining measures }\end{array}$ & $\begin{array}{c}\text { Active } \\
\text { euthanasia }\end{array}$ & $\begin{array}{l}\text { Physician- } \\
\text { assisted suicide }\end{array}$ \\
\hline \multicolumn{6}{|l|}{ Age $\geq 50(v .<50)$ yr } \\
\hline No. (\%) & $1323(90.6)$ & $1304(89.4)$ & $1120(77.0)$ & $790(54.1)$ & 709 (48.9) \\
\hline Crude OR $(95 \% \mathrm{Cl})$ & $1.27(1.02-1.57)$ & $0.83(0.67-1.03)$ & 1.45 (1.24-1.68) & $1.87(1.64-2.13)$ & $1.57(1.38-1.80)$ \\
\hline Adjusted OR $¥(95 \% \mathrm{Cl})$ & $1.42(1.12-1.80)$ & - & $1.46(1.24-1.72)$ & $1.53(1.32-1.78)$ & $1.36(1.17-1.58)$ \\
\hline \multicolumn{6}{|l|}{ Male (v. female) sex } \\
\hline No. (\%) & $1592(88.7)$ & 1652 (91.3) & $1342(74.4)$ & $848(46.9)$ & 791 (43.9) \\
\hline Crude OR $(95 \% \mathrm{Cl})$ & $0.91(0.74-1.11)$ & $1.22(0.98-1.51)$ & $1.19(1.03-1.37)$ & $1.20(1.05-1.36)$ & $1.16(1.02-1.32)$ \\
\hline Adjusted OR $¥(95 \% \mathrm{Cl})$ & - & - & $1.25(1.06-1.47)$ & $1.42(1.23-1.64)$ & $1.31(1.14-1.51)$ \\
\hline \multicolumn{6}{|c|}{$\begin{array}{l}\text { High school education } \\
\text { or lower (v. college or beyond) }\end{array}$} \\
\hline No. $(\%)$ & $1705(89.1)$ & $1701(88.5)$ & $1426(74.4)$ & $1009(52.5)$ & $928(48.4)$ \\
\hline Crude OR $(95 \% \mathrm{Cl})$ & $0.96(0.78-1.18)$ & $0.63(0.51-0.79)$ & $1.20(1.04-1.39)$ & $1.93(1.70-2.20)$ & $1.70(1.49-1.94)$ \\
\hline Adjusted OR $¥(95 \% \mathrm{Cl})$ & - & $0.82(0.63-1.06)$ & $1.08(0.91-1.29)$ & $1.41(1.22-1.63)$ & $1.28(1.01-1.48)$ \\
\hline \multicolumn{6}{|c|}{$\begin{array}{l}\text { Employed (v. not employed) } \\
\text { at diagnosis }\end{array}$} \\
\hline No. (\%) & $1461(88.5)$ & 1501 (89.9) & $1244(74.8)$ & $795(47.8)$ & $744(44.8)$ \\
\hline Crude OR $(95 \% \mathrm{Cl})$ & $0.93(0.75-1.15)$ & $1.02(0.82-1.28)$ & $1.12(0.96-1.30)$ & $1.01(0.88-1.15)$ & $0.97(0.85-1.11)$ \\
\hline Adjusted OR $\ddagger(95 \% \mathrm{Cl})$ & - & - & - & - & - \\
\hline \multicolumn{6}{|l|}{$\begin{array}{l}\text { Having no religion } \\
\text { (v. having a religion) }\end{array}$} \\
\hline No. (\%) & $1053(89.8)$ & $1080(90.8)$ & 885 (74.9) & $558(47.1)$ & $576(48.8)$ \\
\hline Crude OR $(95 \% \mathrm{Cl})$ & $1.08(0.86-1.35)$ & $1.06(0.84-1.35)$ & $1.18(1.01-1.39)$ & $1.15(1.01-1.32)$ & $1.49(1.30-1.72)$ \\
\hline Adjusted OR $¥(95 \% \mathrm{Cl})$ & - & - & $1.21(1.02-1.44)$ & $1.19(1.02-1.32)$ & $1.55(1.30-1.72)$ \\
\hline \multicolumn{6}{|c|}{$\begin{array}{l}\text { Monthly income > } 200 \\
(v . \leq 200) \text {, in } 1000 \text { Korean won }\end{array}$} \\
\hline No. (\%) & $1840(90.2)$ & $1873(91.0)$ & $1520(74.2)$ & $929(45.4)$ & $903(44.3)$ \\
\hline Crude OR $(95 \% \mathrm{Cl})$ & $1.39(1.12-1.73)$ & $1.46(1.17-1.82)$ & $1.07(0.92-1.25)$ & $0.81(0.70-0.93)$ & $0.93(0.81-1.07)$ \\
\hline Adjusted OR $¥(95 \% \mathrm{Cl})$ & $1.44(1.15-1.81)$ & $1.43(1.14-1.79)$ & - & $0.98(0.84-1.14)$ & - \\
\hline \multicolumn{6}{|c|}{$\begin{array}{l}\text { Note: } \mathrm{Cl}=\text { confidence interval, } \mathrm{OR}=\text { odds ratio. } \\
\text { *Participants who responded "strongly agree" or "agree" to questions about the interventions studied were considered to approve of the interventions. } \\
\text { †Answers about characteristics were dichotomized for this analysis. } \\
\text { †Adjusted for variables listed in this table. Adjusted ORs are presented only for variables with statistically significant crude ORs. }\end{array}$} \\
\hline
\end{tabular}


life-sustaining treatment $(87.1 \%-94.0 \%)$ and the practice of active pain control $(89.0 \%-98.4 \%)$ despite the associated risk of life-shortening effects (Figure 1, Table 3). A smaller majority $(60.8 \%-76.0 \%)$ approved of the withholding of life-sustaining measures. About $50 \%$ of those in the patient and general public groups supported active euthanasia and physician-assisted suicide, as compared with less than $40 \%$ of the family caregivers and less than $10 \%$ of the oncologists.

\section{Interpretation}

In this survey of attitudes toward critical interventions at the end of life of terminally ill patients, the most interesting finding was that most of the participants in each of the four study groups - patients, family caregivers, oncologists and members of the general public showed a positive attitude toward the withdrawal of futile life-sustaining treatment and the practice of active pain control.

These findings suggest that recent debates about death with dignity and a generalized desire to counter "bad" ways of dying have influenced opinion. ${ }^{4,22,23}$ In the absence of effective palliation, it is no surprise that patients and others would choose a route that avoids the prolongation of suffering. Palliative care was introduced to Korea recently but is still rare, and practical services are provided mainly by oncologists or family physicians in inpatient care units.

Overall, the attitudes of the group representing the general public were similar to those of the cancer patients. This similarity might be explained by the general public's empathy for patients with terminal illness. Whereas the patients and the members of the general public appeared to support patient autonomy and hastening of the dying process, the oncologists and family caregivers who participated in the survey had more negative attitudes. Their attitudes might be influenced by uncertainty about the prognosis, religious beliefs, fear of pressure on vulnerable patients and legal circumstances. ${ }^{5}$

In Korea, where advance directives are not legally binding, the withholding or withdrawal of futile life-sustaining treatment according to a patient's wishes is controversial, and it is not dealt with in medical training programs. In our study, however, oncologists were the group that was most accepting of the withdrawal of futile lifesustaining treatment and the practice of active pain control. These findings suggest that oncologists have an interest in improving end-of-life care, as is supported by physicians working in voluntary hospice services in the United Kingdom. ${ }^{24}$

In our survey, attitudes toward acceptance of euthanasia and physician-assisted suicide were associated with age, sex and religious belief. In most other studies, however, sex was not a major influential factor, ${ }^{14,15,20,25}$ and the effect of age was inconsistent. ${ }^{9,14,20}$ As people age, they are confronted with deteriorating health and the death of friends or family members; thus, they may be expected to support the easing of dying through withdrawal of life-sustaining treatment and physician-assisted suicide..$^{59}$ These findings suggest that the shift in attitudes comes from the experiences of an aging population rather than from the younger generation's "new ideas."

We found that religious belief correlated significantly and negatively with acceptance of interventions used for terminally ill patients at the end-of-life. This observation supports previous findings that religion is a strong determinant of the attitudes of patients, ${ }^{11,14,17,20,26}$ oncologists, ${ }^{9,11,17,27}$ family caregivers ${ }^{20,25}$ and the general public., ${ }^{411,17} \mathrm{We}$ found that participants with lower education levels were more supportive of active

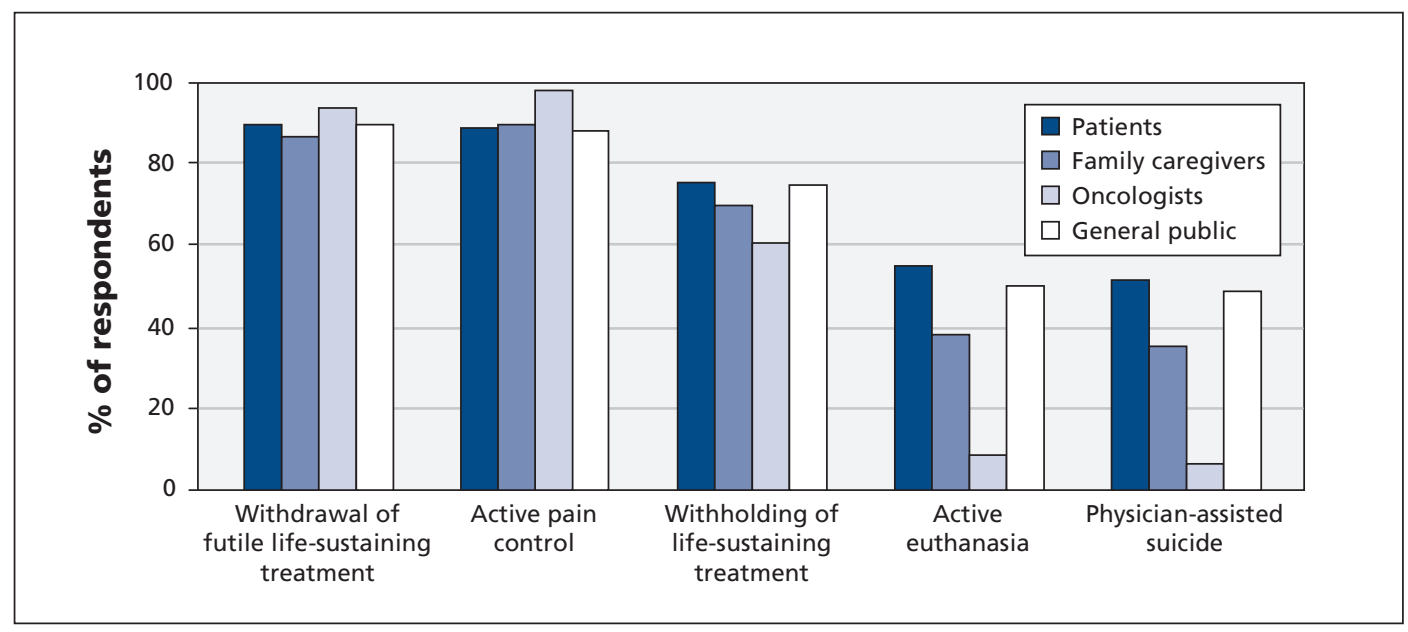

Figure 1: Proportion of respondents who approved of critical interventions at the end of life of terminally ill patients, by participant group. 
euthanasia and physician-assisted suicide than were more educated participants. It is interesting that religion and education correlated similarly with attitude toward euthanasia. These findings warrant further study for confirmation.

Although there has been concern in the United States that poor people would be more likely than those in higher income groups to choose a hastened death, ${ }^{21}$ we found no association between monthly income and attitude toward any of the life-ending interventions studied. In Korea, there are few uninsured people. National health insurance, together with medicare for low-income people, covers almost the whole population. Especially for cancer, coverage is high, and the patient's out-of-pocket share was $10 \%$ in 2000 and decreased to $5 \%$ in 2010 . That helps explain the lack of an association between income and support for physician-assisted suicide and euthanasia. ${ }^{28}$ In contrast, higher income was associated with approval of the withdrawal of futile lifesustaining treatment and the practice of active pain control. These findings suggest that the association between income and end-of-life interventions varies by type of intervention.

Surveys conducted in other countries have reported that $60 \%-90 \%$ of patients support euthanasia or physician-assisted suicide, ${ }^{8,14-17,20}$ as compared with only about $50 \%$ of patients in our study. The relatively higher proportion of negative attitudes in Korea toward the hastening of death of terminally ill patients could possibly be ascribed to different cultural attitudes toward personal autonomy. Earlier empirical studies, especially those from Western countries, generally showed an increase in public acceptance of euthanasia that might be explained by a rising belief in personal autonomy regarding end-oflife decisions and the individualism that has been increasing over the last two decades. ${ }^{4}$ It is under-

\begin{tabular}{|c|c|c|c|c|}
\hline \multirow[b]{2}{*}{ Intervention } & \multicolumn{4}{|c|}{ Group; $\%$ of respondents } \\
\hline & Patients & $\begin{array}{l}\text { Family } \\
\text { caregivers }\end{array}$ & Oncologists & $\begin{array}{l}\text { General } \\
\text { public }\end{array}$ \\
\hline $\begin{array}{l}\text { Withdrawal of futile } \\
\text { life-sustaining treatment }\end{array}$ & 89.9 & 87.1 & 94.0 & 89.8 \\
\hline Active pain control & 89.7 & 90.4 & 98.4 & 89.0 \\
\hline $\begin{array}{l}\text { Withholding of } \\
\text { life-sustaining measures }\end{array}$ & 76.0 & 70.3 & 60.8 & 74.9 \\
\hline Active euthanasia & 55.3 & 38.4 & 8.3 & 50.4 \\
\hline Physician-assisted suicide & 51.7 & 35.6 & 6.3 & 49.2 \\
\hline
\end{tabular}

standable, then, that euthanasia is more acceptable in those parts of the world that traditionally favour personal autonomy (e.g., North America and Europe) and less acceptable in parts that favour more paternalistic or family-centred models of decision-making (e.g., Asia).

Our finding that oncologists were more negative than the other study groups toward euthanasia and physician-assisted suicide supports findings from the Netherlands, the United States ${ }^{15}$ and the United Kingdom. ${ }^{26}$ Moreover, oncologists in the United States and Europe are reluctant to accede to requests of terminally ill patients to help hasten death, probably because they will be held accountable for the deaths. ${ }^{59,21}$ Other reasons might be a belief that symptoms can be controlled without resorting to euthanasia or, perhaps, the honouring of the Hippocratic oath.

\section{Limitations}

Our study has several limitations. First, we enrolled only cancer patients, their family caregivers and oncologists from university hospitals, so our results may not be generalizable to other treatment settings or to other terminal illnesses. The nature of cancer is such, however, that most patients are likely to face the end-of-life issues discussed here.

Second, we interviewed the patients, family caregivers and oncologists in person, whereas the members of the general public were surveyed by telephone. This difference may have lessened the validity of the comparisons. However, we used a model based on identical study designs and questionnaires for all participating groups in an attempt to overcome this shortcoming.

Third, although there was no obligation to participate in the survey, the response rates in the patient and family caregiver groups were very high. High response rates are not usual for surveys in Korea; however, in our study, the patients' oncologists recommended participation, which may have caused the patients and their family caregivers to feel a sense of obligation. It may also have caused patients to provide answers that the survey seemed to want.

Fourth, although the questionnaire in our survey was designed on the basis of those used in previous studies of this issue, ${ }^{5,911,20,21}$ it was not validated separately.

Fifth, we did not analyze the attitudes of patients by their stage of cancer. Those who knew they were dying may have had different opinions from those hopeful in the face of a new diagnosis. Further study is needed for confirmation.

Finally, we did not include in the database any important variables - such as the participants' own experiences with chronic or critical 
diseases, their experiences of caring for family members or loved ones, or their being cared for by family members. Including those variables in the multiple logistic regression analysis might have changed the results.

\section{Conclusion}

Our study suggests that, although the various participant groups shared the same attitude toward futile and ameliorative end-of-life care (the withdrawal of futile life-sustaining treatment and the use of active pain control), oncologists had a more negative attitude than those in the other groups toward the active ending of life (euthanasia and physician-assisted suicide).

\section{References}

1. Murray SA, Boyd K, Sheikh A. Palliative care in chronic illness BMJ 2005;330:611-2.

2. Quill TE. Dying and decision making - evolution of end-of-life options. N Engl J Med 2004;350:2029-32.

3. Corn BW. Ending end-of-life phobia - a prescription for enlightened health care reform. N Engl J Med 2009;361:e63.

4. Cohen J, Marcoux I, Bilsen J, et al. Trends in acceptance of euthanasia among the general public in 12 European countries (1981-1999). Eur J Public Health 2006;16:663-9.

5. Gielen J, Van Den Branden S, Broeckaert B. Attitudes of European physicians toward euthanasia and physician-assisted suicide: a review of the recent literature. J Palliat Care 2008;24:173-84.

6. van der Maas PJ, Pijnenborg L, van Delden JJ. Changes in Dutch opinions on active euthanasia, 1966 through 1991. JAMA 1995;273:1411-4.

7. Benson JM. The polls-trends - end-of-life issues. Public Opin $Q$ 1999;63:263-77.

8. Blendon RJ, Szalay US, Knox RA. Should physicians aid their patients in dying? The public perspective. JAMA 1992;267: 2658-62.

9. Meier DE, Emmons CA, Wallenstein S, et al. A national survey of physician-assisted suicide and euthanasia in the United States. N Engl J Med 1998;338:1193-201.

10. Blizzard R. Canadians and the ethics of euthanasia. Gallup; 2002 July 23. Available: www.gallup.com/poll/6442/Canadians-Ethics -Euthanasia.aspx (accessed 2011 May 19).

11. Myo-ja S. Top court upholds "die with dignity" right. JoongAng Daily 2009; May 22.

12. Yun YH, Park SM, Lee K, et al. Predictors of prescription of morphine for severe cancer pain by physicians in Korea. Ann Oncol 2005;16:966-71.

13. van der Heide A, Onwuteaka-Philipsen BD, Rurup ML, et al. End-of-life practices in the Netherlands under the Euthanasia Act. N Engl J Med 2007;356:1957-65.

14. Suarez-Almazor ME, Newman C, Hanson J, et al. Attitudes of terminally ill cancer patients about euthanasia and assisted suicide: predominance of psychosocial determinants and beliefs over symptom distress and subsequent survival. J Clin Oncol 2002;20:2134-41.

15. Wolfe J, Fairclough DL, Clarridge BR, et al. Stability of attitudes regarding physician-assisted suicide and euthanasia among oncology patients, physicians, and the general public. J Clin Oncol 1999; $17: 1274$.

16. Sullivan M, Rapp S, Fitzgibbon D, et al. Pain and the choice to hasten death in patients with painful metastatic cancer. $J$ Palliat Care 1997; 13:18-28.

17. Emanuel EJ, Fairclough DL, Daniels ER, et al. Euthanasia and physician-assisted suicide: attitudes and experiences of oncology patients, oncologists, and the public. Lancet 1996;347:1805-10.

18. Suarez-Almazor ME, Belzile M, Bruera E. Euthanasia and physician-assisted suicide: a comparative survey of physicians, terminally ill cancer patients, and the general population. J Clin Oncol 1997; $15: 418-27$

19. Levy PS, Lemeshow LS. Sampling of populations: methods and applications. 4th ed. New York (NY): John Wiley and Sons; 2009.

20. Emanuel EJ, Fairclough DL, Emanuel LL. Attitudes and desires related to euthanasia and physician-assisted suicide among terminally ill patients and their caregivers. JAMA 2000;284:2460-8.

21. Ganzini L, Nelson HD, Schmidt TA, et al. Physicians' experiences with the Oregon Death with Dignity Act. N Engl J Med 2000;342: 557-63.

22. Legalize the right to die. Korea JoongAng Daily 2009; May 20 Available: http://joongangdaily.joins.com/article/view.asp?aid =2905031 (accessed 2011 May 16).

23. Seale C, Addington-Hall J, McCarthy M. Awareness of dying: prevalence, causes and consequences. Soc Sci Med 1997;45:477-84.

24. Addington-Hall JM, Karlsen S. A national survey of health professionals and volunteers working in voluntary hospice services in the UK. I. Attitudes to current issues affecting hospices and palliative care. Palliat Med 2005; 19:40-8.

25. Bachman JG, Alcser KH, Doukas DJ, et al. Attitudes of Michigan physicians and the public toward legalizing physician-assisted suicide and voluntary euthanasia. N Engl J Med 1996;334:303-9.

26. Ganzini L, Johnston WS, McFarland BH, et al. Attitudes of patients with amyotrophic lateral sclerosis and their care givers toward assisted suicide. N Engl J Med 1998;339:967-73.

27. Field MJ, Cassel CK. Approaching death: improving care at the end of life. Washington (DC): National Academy Press; 1997.

28. Jeong HS. Korea's National Health Insurance - lessons from the past three decades. Health Aff (Millwood) 2011;30:136-44.

Affiliations: From the Cancer Management Branch (Yun, Han) and the Cancer Registration and Statistics Branch (S. Park), Research Institute, National Cancer Center, Goyang, Korea; the Department of Surgery (B.W. Park), Yonsei University Medical Center, Yonsei University College of Medicine, Seoul, Korea; the Department of Obstetrics and Gynecology (Cho), School of Medicine, Keimyung University, Daegu, Korea; the Department of Surgery (S. Kim), Samsung Medical Center, Sungkyunkwan University, School of Medicine, Seoul, Korea; the Quality of Life Improvement Team and Department of Oncology (D.H. Lee), University of Ulsan College of Medicine, Asan Medical Center, Seoul, Korea; the Section of Medical Oncology (S.N. Lee), Department of Internal Medicine, Ewha Womans University School of Medicine, Seoul, Korea; the Department of Surgery (E.S. Lee), Anam Medical Center, Korea University, School of Medicine, Seoul, Korea; the Department of Internal Medicine (Kang), Postgraduate Medical School, Gyeongsang National University, Jinju, Korea; the Departments of Medical Oncology and Hematology (Si-Young Kim), Kyung Hee University Hospital, Seoul, Korea; the Department of Hemato-oncology (J.L. Lee), Fatima Hospital, Daegu, Korea; the Division of Hemato-oncology (Heo), Department of Internal Medicine, Seoul National University Hospital, Seoul, Korea; the Department of Radiation Oncology (C.G. Lee), Yonsei University College of Medicine, Yonsei Cancer Center, Seoul, Korea; the Kwangju Christian Hospital (Lim), Kwangju, Korea; the Division of Hemato-oncology (Sam Yong Kim), Department of Internal Medicine, College of Medicine Chungnam National University, Daejeon, Korea; the Department of Hemato-oncology (Choi), Gangneung Asan Hospital, Asan University School of Medicine, Gangneung, Korea; the Pohang Sunlin Hospital (Jeong), Pohang, Korea; and the Department of Radiation Oncology (Chun), Ajou University School of Medicine, Suwon, Korea

Contributors: Young Ho Yun and Kyung Hee Han contributed substantially to the conception and design of the study. Byeong Woo Park, Chi-Heum Cho, Sung Kim, Dae Ho Lee, Soon Nam Lee, Eun Sook Lee, Jung Hun Kang, SiYoung Kim, Jung Lim Lee, Dae Seog Heo, Chang Geol Lee, Yeun Keun Lim, Sam Yong Kim, Jong Soo Choi, Hyun Sik Jeong and Mison Chun contributed to data collection. Young Ho Yun, Kyung Hee Han and Sohee Park analyzed and interpreted the data. All of the authors participated in the drafting of the manuscript and its revision, and all gave their final approval of the version submitted for publication.

Funding: This work was supported by the 2008 Korean National Cancer Control Program by the Korean Ministry for Health, Welfare and Family Affairs, and in part by a grant from the Korean National Cancer Center (grant no. 0710730-3).

Acknowledgement: We thank Dr. Miriam Bloom (SciWrite Biomedical Writing \& Editing Services) for professional editing. 